\title{
DNA hydrolysing IgG catalytic antibodies: an emerging link between psychoses and autoimmunity
}

\author{
Rajendran Ramesh ${ }^{1}$, Aparna Sundaresh ${ }^{2}$, Ravi Philip Rajkumar ${ }^{3}$, Vir Singh Negi ${ }^{2}$, M. A. Vijayalakshmi ${ }^{1}$, Rajagopal Krishnamoorthy ${ }^{4}$,
} Ryad Tamouza ${ }^{4,5,6,7}$, Marion Leboyer ${ }^{4,5,6,7}$ and A. S. Kamalanathan (iD)

It is not uncommon to observe autoimmune comorbidities in a significant subset of patients with psychotic disorders, namely schizophrenia (SCZ) and bipolar disorder (BPD). To understand the autoimmune basis, the DNA abyzme activity mediated by serum polyclonal IgG Abs were examined in psychoses patients, quantitatively, by an in-house optimized DNase assay. A similar activity exhibited by IgG Abs from neuropsychiatric-systemic lupus erythematosus (NP-SLE) patients was used as a comparator. Our data revealed that the IgG DNase activity of SCZ was close to that of NP-SLE and it was twofold higher than the healthy controls. Interestingly, the association between DNase activity with PANSS (positive, general and total scores) and MADRS were noted in a subgroup of SCZ and BPD patients, respectively. In our study group, the levels of IL-6 and total lgG in BPD patients were higher than $\mathrm{SCZ}$ and healthy controls, indicating a relatively inflammatory nature in BPD, while autoimmune comorbidity was mainly observed in SCZ patients.

npj Schizophrenia (2021)7:13; https://doi.org/10.1038/s41537-021-00143-6

\section{INTRODUCTION}

Growing evidence indicate that neuroinflammation and immune dysfunction play a role in the clinical manifestations of psychotic disorders viz. schizophrenia (SCZ) and bipolar disorder (BPD) ${ }^{1-3}$. Besides, frequent association of autoimmune comorbidities are also reported in psychotic disorders ${ }^{4}$. Raised levels of C-reactive protein and pro-inflammatory cytokines viz. interleukin-2 (IL-2), IL6 , interferon- $\gamma$, tumour necrosis factor- $a$, in the patients' serum are markedly associated with psychotic syndromes i.e., mania, depression, etc ${ }^{5}$. Epidemiological studies emphasise the involvement of an autoimmune drive in the disease manifestations of SCZ and BPD patients ${ }^{6}$. From a clinical perspective, the psychotic disorders presents several parallels to autoimmune diseases like early-onset, immune dysregulation, the incidence of alternating active-remission disease courses and prevalence of autoantibodies (Aabs) ${ }^{7}$. Further, genetic association studies along with the impact of environmental factors (infectious stigma, social stress) raise the plausibility that the autoimmune response are either predisposed or proactive in these disorders ${ }^{8,9}$. Interestingly, administration of few immunosuppressive drugs, used in autoimmune pathologies, seems to attenuate psychotic symptoms in a subset of psychiatric patients ${ }^{10}$. The occurrence of Aabs in the blood of a significant subset of psychotic patients suggests the involvement of humoral autoimmunity, which might contribute to psychotic manifestations and disease severity ${ }^{11,12}$. Intriguingly, the occurrence of IgG Aabs against neurotransmitter receptors and other macromolecules (DNA, brain lipids, gangliosides, and cardiolipin) has been described in a proportion of SCZ and BPD patients ${ }^{13,14}$. Particularly, IgG Aabs against neuronal receptors like N-methyl-Daspartate receptor (NMDAR), $\gamma$-aminobutyric acid receptor (GABAR), and a-amino-3-hydroxy-5-methyl-4-isoxazolepropionic acid receptor (AMPAR) have been observed during the psychotic crisis $^{15,16}$. Also, a systematic study by Pearlman and Najjar revealed a high prevalence of anti-NMDAR lgG Abs in SCZ patients and to a lesser extent in BPD patients ${ }^{17}$.

Above facts suggest a potential overlap between psychotic syndromes and autoimmunity. Despite these clues, the knowledge about the autoimmune processes at play in psychiatric disorders remains elusive. Use of conventional diagnostic criteria, Diagnostic and Statistical Manual of Mental disorders (DSM) for the assessment of psychotic syndrome; presence or absence of Aabs, age of onset, clinical presentations and non-interventional clinical investigations, do not fully take into account the autoimmunity based differentiation of the syndromes. Such a gap led to the recent update of the criteria for the diagnosis and disease classification, published in the recent position paper by Pollack et al. $^{18}$. This update takes into consideration the autoimmunity based risks in psychiatric syndrome as well as its influence on disease mediation. This has led to the establishment of a new disease category represented as "autoimmune psychosis". Any biomarker that could stratify this category more objectively is of great interest not only to expand the horizon of autoimmune concept in a subset of psychoses, but also to tailor some evidencebased individualised therapeutic strategies.

Robust association of psychiatric symptoms in diverse autoimmune diseases viz. multiple sclerosis (MS), scleroderma, antiphospholipid syndrome, and systemic lupus erythematosus (SLE) have also been reported ${ }^{19,20}$. Especially in case of MS and neuropsychiatric systemic lupus erythematosus (NP-SLE), along with conventional Aabs (anti-nuclear Abs, anti-dsDNA Abs), presence of neuronal Aabs (anti-NMDAR) is demonstrated and this may contribute to the observed psychotic/central nervous system (CNS) manifestations ${ }^{21-24}$.

The biological function of Aabs in autoimmune diseases, beyond simple antigen recognition, sometimes attributes for high order function i.e., catalysis. Fascinatingly, such cognate Abs

${ }^{1}$ Centre for BioSeparation Technology, Vellore Institute of Technology (VIT), Vellore, Tamil Nadu, India. ${ }^{2}$ Department of Clinical Immunology, Jawaharlal Institute of Postgraduate Medical Education \& Research (JIPMER), Puducherry, India. ${ }^{3}$ Department of Psychiatry, Jawaharlal Institute of Postgraduate Medical Education \& Research (JIPMER), Puducherry, India. ${ }^{4}$ Fondation FondaMental, Créteil, France. ${ }^{5}$ Department of Psychiatry and Addictology, Mondor University Hospital, AP-HP, DMU IMPACT, Créteil, France. ${ }^{6}$ University Paris-

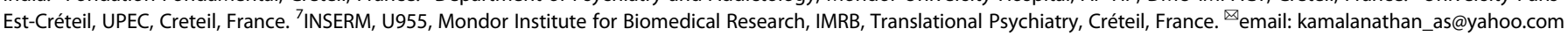


exhibit proteolytic, DNase and RNase activity, which are wellproven to be an intrinsic property and such Abs are referred to as catalytic Abs or natural abzymes ${ }^{25}$. These Abs are capable of

Table 1. Demographic and clinical profile.

\begin{tabular}{|c|c|c|c|c|}
\hline Patients and variables & $\begin{array}{l}\mathrm{SCZ} \\
(n=31)\end{array}$ & $\begin{array}{l}\text { BPD } \\
(n=31)\end{array}$ & $\begin{array}{l}\text { NP-SLE } \\
(n=20)\end{array}$ & $\begin{array}{l}\mathrm{HC} \\
(n=25)\end{array}$ \\
\hline \multicolumn{5}{|l|}{ Demographic } \\
\hline Age & $35.1 \pm 7.5^{\mathrm{a}}$ & $31.2 \pm 9.9$ & $28 \pm 9.13$ & $34.9 \pm 8.1$ \\
\hline $\operatorname{Sex}(\% \mathrm{~F})$ & 58 & 52 & 95 & 52 \\
\hline Body mass index & $23.15 \pm 4.9$ & $22.3 \pm 3.8$ & - & $23.1 \pm 3.6$ \\
\hline Disease status-acute (\%) & 58 & 61 & $\begin{array}{l}\text { Active CNS } \\
\text { disease }\end{array}$ & - \\
\hline Disease duration (months) & $10.1 \pm 9.9$ & $5.5 \pm 6.7$ & $13.6 \pm 6.5$ & - \\
\hline Smoking (\%) & $25.8(8)$ & $22.6(7)$ & 0 & 12 \\
\hline Age of onset (years) & $26.88 \pm 7.8$ & $22.4 \pm 4.7$ & $27.6 \pm 2.7$ & - \\
\hline \multicolumn{5}{|l|}{ Medication $^{\mathrm{b}}$} \\
\hline Antipsychotic typical (\%) & 54.83 & 68 & - & - \\
\hline Antipsychotic atypical (\%) & 45.16 & 20 & - & - \\
\hline Mood stabiliser (\%) & 3.2 & 92 & - & - \\
\hline $\begin{array}{l}\text { Immunomodulators/ } \\
\text { Immunosupressive drugs (\%) }\end{array}$ & - & - & 65 & - \\
\hline Mycofenolate Mofetil (\%) & - & - & 15 & - \\
\hline Cyclophosphamide (\%) & - & - & 20 & - \\
\hline Methotrexate (\%) & - & - & 20 & - \\
\hline Steroids (\%) & - & - & 50 & - \\
\hline \multicolumn{5}{|l|}{ Measure of symptoms } \\
\hline PANSS total & $64.4 \pm 23.2$ & - & - & - \\
\hline MADRS & - & $3.4 \pm 6.5$ & - & - \\
\hline YMRS & - & $15.5 \pm 10.5$ & - & - \\
\hline FAST & $42.06 \pm 22.8$ & $42.6 \pm 15.1$ & - & - \\
\hline GAF & $45.4 \pm 20.7$ & $49.7 \pm 12.3$ & - & - \\
\hline \multicolumn{5}{|l|}{ Infectious agents } \\
\hline HERV-W \% positive $(n)$ & $6.5(2)$ & $3.2(1)$ & - & - \\
\hline CMV \% positive $(n)$ & $16(5)$ & $25.8(8)$ & - & $4(1)$ \\
\hline $\begin{array}{l}\text { Toxoplasma Gondi \% positive } \\
(n)\end{array}$ & $22.6(7)$ & $12.9(4)$ & - & $8(2)$ \\
\hline \multicolumn{5}{|c|}{ 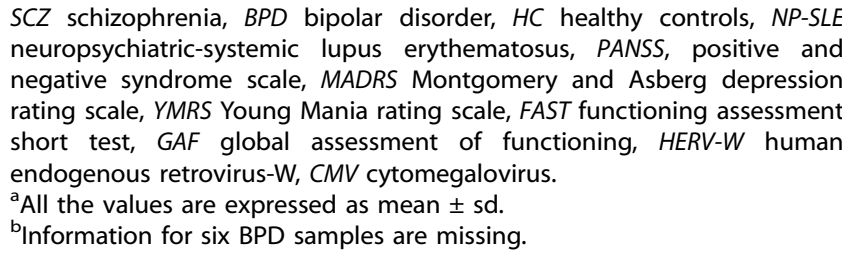 } \\
\hline
\end{tabular}

modifying the self-antigens (proteins and nucleic acids) chemically like that of naturally occurring enzymes ${ }^{26}$. Exposing the conserved or modified motifs of the endogenous antigens to the immune system can randomly elicit the generation of anti-idiotypic Abs (Aabs) endowed with enzymatic properties. It is very likely by this mechanism, the abzymes may participate not only in the host defence but also when go awry, can drive the inflammatory or autoimmune process. In autoimmune diseases like MS, thyroiditis, acquired haemophilia, SLE, rheumatoid arthritis, systemic sclerosis, the Abs not only recognise the endogenous macromolecules like myelin basic protein, thyroglobulin, Factor VIII, DNA and RNA molecules but also are capable of hydrolysing them ${ }^{27-29}$. Whether the evaluation of abzyme function would add value, directly or indirectly, to the current arsenal of psychosis criteria and/or for stratification of the psychosis spectrum, remains to be studied.

At this end, we initiated a comparative study to evaluate quantitatively the DNA abzyme function of IgG Abs from SCZ, BPD, and NP-SLE patients along with healthy controls. Additionally, anti-dsDNA Abs titre, total IgG, and IL-6 levels were measured and compared in three disease groups along with healthy controls. Further, the relationship between DNase activity with psychotic disease scores and immunological parameters were examined, to decipher the association of autoimmune spectrum in psychoses.

\section{RESULTS \\ Clinical profile}

Table 1 briefs the biochemical and demographic profile of the study participants. Table 2 represents the inflammation status (IL-6, serum IgG level) and autoantibody profile (ANA, anti-dsDNA) of the patients.

\section{Purification of IgG Abs}

To investigate the presence of DNA hydrolysing activity, polyclonal IgG Abs were recovered from the serum of SCZ, BPD, NP-SLE patients, and the healthy controls. Here, CIM ${ }^{\circledast}$ disk coupled with the bio-affinity ligand, L-histidine, was used for the recovery of total IgG Abs directly from the serum, in a single-step (Fig. 1). The SDS-PAGE analysis (Fig. 2a) under non-reducing conditions revealed an intact lgG molecule $(150 \mathrm{KDa})$ in the eluted peak fractions (Fig. 1, label E). As expected, under reducing conditions (Fig. 2b) two bands corresponding to heavy (50 KDa) and light chains $(25 \mathrm{KDa})$ of $\mathrm{IgG}$ Abs were prominent. Under similar conditions the therapeutic intravenous immunoglobulin (IVIg) was also subjected to purification. Overall, the antibody preparation was found to be homogenous and was used for further analysis.

Table 2. Immunological analysis.

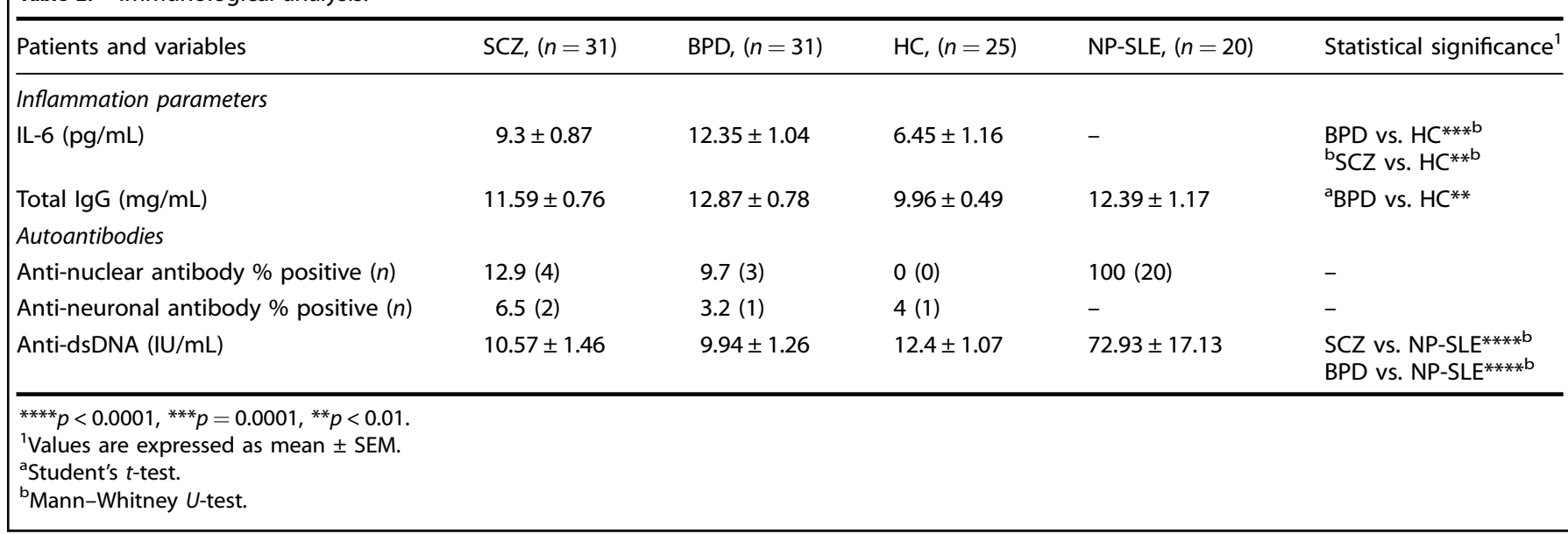




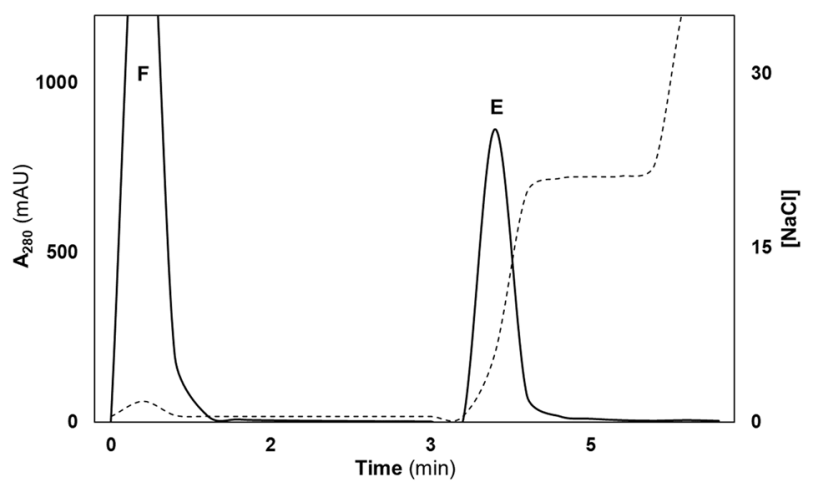

Fig. 1 A typical chromatogram of total IgG purified from serum on a CIM-histidyl disk. About $150 \mu \mathrm{L}$ serum (tenfold dilution) in binding buffer, $25 \mathrm{mM}$ MOPS buffer $\mathrm{pH} 6.5$ was injected and the bound proteins were eluted with $25 \mathrm{mM} \mathrm{MOPS} \mathrm{pH} 6.5+0.4 \mathrm{M} \mathrm{NaCl}$. Flow rate: $4 \mathrm{~mL} / \mathrm{min}$. Peaks, $\mathrm{F}$ and $\mathrm{E}$ represent flow-through and elution, respectively.
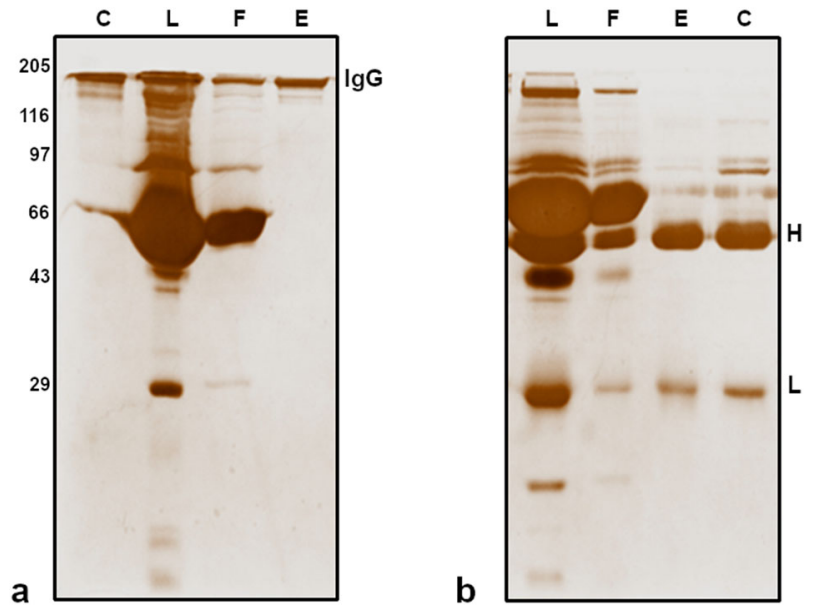

Fig. 2 SDS-PAGE (10\%) analysis. a Non-reducing conditions, b reducing conditions. Lanes: C-human IgG, Cohn fraction (II, III), L-total serum, F-flow-through and E-elution ( $0.2 \mathrm{M} \mathrm{NaCl})$. $\mathrm{H}$ and $\mathrm{L}$ correspond to heavy chain $(50 \mathrm{KDa})$ and light chain $(25 \mathrm{KDa})$ of IgG. Gels were derived from the same experiment.

\section{DNA hydrolysis assay}

The DNA hydrolysing activity by polyclonal IgG Abs from the $S C Z$, BPD, and NP-SLE patients along with the healthy controls are illustrated in Fig. 3. Remarkably, both SCZ and BPD IgG Abs revealed DNA hydrolysing activity while the healthy controls and IVlg showed a non-negligible activity. The plasmid DNA hydrolysis mediated by lgG Abs progressed in a pronounced manner with relative disappearance of the supercoiled form (sc) and the appearance of the relaxed form ( $\mathrm{rc}$ ) followed by linear form (In), notably in the SCZ, BPD, and NP-SLE samples. However, the IgG Abs from the disease groups exhibited differences in the rate of hydrolysis, wherein few SCZ and NP-SLE samples showed rapid hydrolysis of the DNA.

\section{Antibody concentration and time-dependent assay for DNA hydrolysis}

To measure IgG mediated DNA hydrolysis quantitatively, the IgG Abs concentration and time course required for the hydrolysis of a fixed concentration of DNA were determined. First, we determined the IgG Abs concentration required for hydrolysing DNA in each study group. Figure $4 a$ is a schematic representation of the DNA hydrolysed by increasing concentration of affinity purified IgG Abs from the disease groups and the healthy controls. Agarose gel data (not shown) was used to compute the hydrolysis percentage, mainly the scDNA, by densitometry analysis. Results revealed that $1 \mu \mathrm{g}$ of $\lg \mathrm{Abs}$ were adequate to quantitatively measure the scDNA hydrolysis.

Subsequently, time point assay (Fig. 4b) was performed with $1 \mu \mathrm{g}$ IgG Abs from disease samples and healthy controls. In the agarose gel (not shown), a pattern of steady decrease (since hydrolysed) in the scDNA was noted with increasing time of incubation that was quantified by densitometry. The percentage hydrolysis was calculated by subtracting the quantified values of residual scDNA from the amount of intact scDNA (incubated without IgG Abs), at respective time points. Interestingly, the activity data of IgG Abs from the SCZ group was proportionately close to the activity exhibited by IgG Abs from the NP-SLE group.

These functional assays allowed to quantitate the lgG mediated DNA hydrolysing activity (ng DNA/ $\mu \mathrm{g} \lg \mathrm{Abs} / \mathrm{h}$ ) exhibited by patients in the disease groups, healthy controls and IVlg sample (Fig. 5). One-way ANOVA analysis was used for the comparison of the activity between the four groups. The ANOVA analysis revealed significance with $p=0.0003$ and degree of freedom

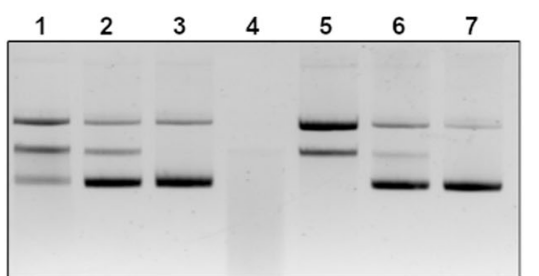

a

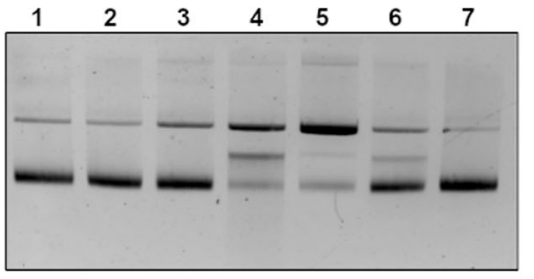

C

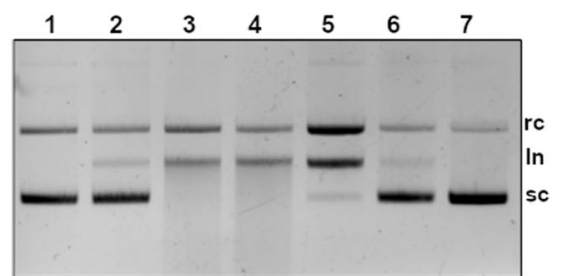

b

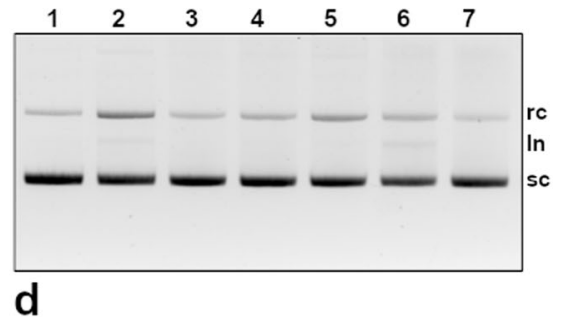

Fig. 3 DNA hydrolysis by total IgG antibody. a-d Neuropsychiatric systemic lupus erythematosus (NP-SLE), schizophrenia (SCZ), bipolar disorder (BPD), and healthy control (HC) samples, respectively. Plasmid DNA, pUC18 (50 ng) was incubated with lgG $(2 \mu \mathrm{g})$ for $2 \mathrm{~h}$ at $37^{\circ} \mathrm{C}$ and visualised by ethidium bromide stain. Lanes: 1-5, IgG from patients; 6, IVlg \& 7, DNA incubated alone. sc supercoiled DNA, rc relaxed circular DNA, In linear DNA. 
a

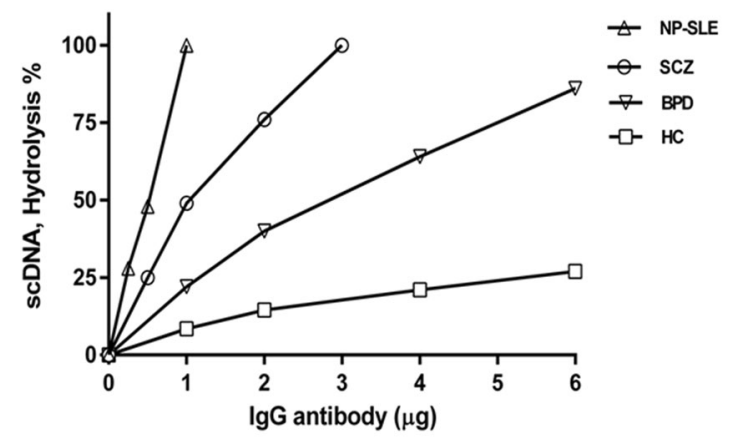

b

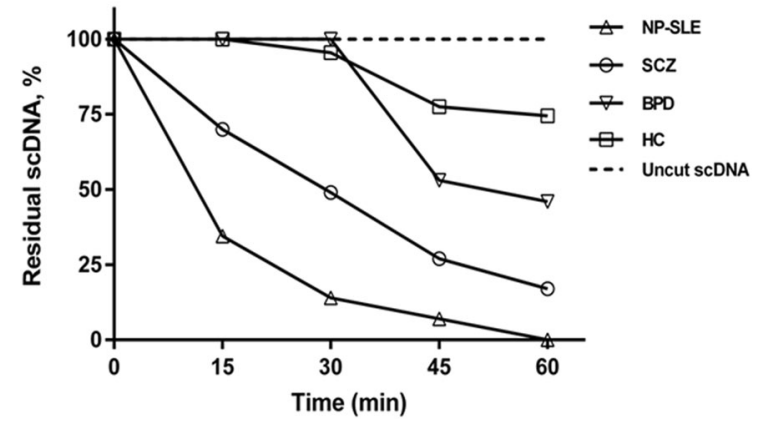

Fig. 4 Antibody concentration and time-dependent optimisation assays. a Optimisation of IgG concentration: plasmid DNA (50 ng) was incubated with increasing concentration of $\operatorname{lgG}(1-6 \mu \mathrm{g})$ for $2 \mathrm{~h}$ at $37^{\circ} \mathrm{C}$. b Time-point assay: fixed concentration of lgG $(1 \mu \mathrm{g})$ was incubated with plasmid DNA (50 ng). Aliquots were analysed on an agarose gel $(0.8 \%)$ and the scDNA hydrolysis was estimated by densitometry analysis (Image Lab ${ }^{\mathrm{TM}}$ 6.0.1, BioRad). NP-SLE neuropsychiatric systemic lupus erythematosus, SCZ schizophrenia, BPD bipolar disorder, $\mathrm{HC}$ healthy control.

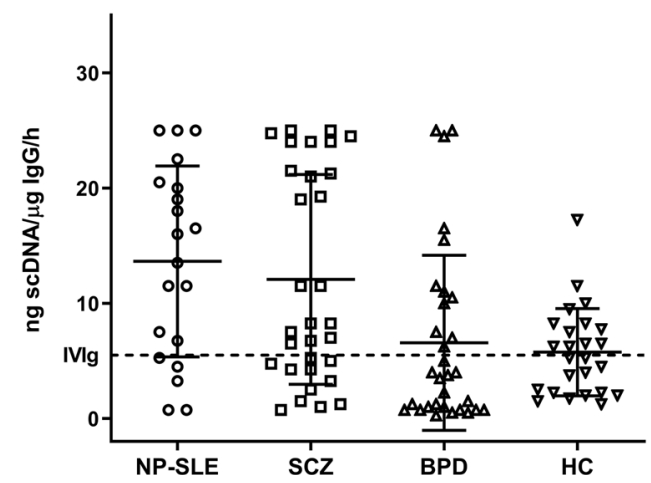

Fig. 5 Comparative analysis of IgG mediated DNA hydrolysis. IgG $(1 \mu \mathrm{g})$ was incubated with plasmid DNA $(50 \mathrm{ng})$ for $1 \mathrm{~h}$ at $37^{\circ} \mathrm{C}$ and hydrolysed products were analysed on $0.8 \%$ agarose gel. scDNA hydrolysis was determined and calculated by densitometry analysis (Image Lab ${ }^{\mathrm{TM}}$ 6.0.1, Bio-Rad). One-way ANOVA analysis revealed a significance between the groups with $F(3,103)=6.792, p=0.0003$. IVIg (----), NP-SLE neuropsychiatric systemic lupus erythematosus $(n=20)$, SCZ schizophrenia $(n=31)$, BPD bipolar disorder $(n=31)$, $\mathrm{HC}$ healthy control $(n=25)$.

$F(3,103)=6.792$. Based on the central tendency value (mean $\pm \mathrm{sd})$ highest DNase activity, as expected, was noted in NP-SLE (13.6 \pm 8.7) and successively followed by SCZ (12.1 \pm 9.2$)$, BPD $(6.5 \pm 7.6)$ and healthy control $(5.7 \pm 3.7)$.

Of further interest, the immunological analysis revealed a low titre of anti-dsDNA Abs in both SCZ and BPD patients on contrary to NP-SLE patients (Table 2). Both the IL-6 and IgG levels exemplify a

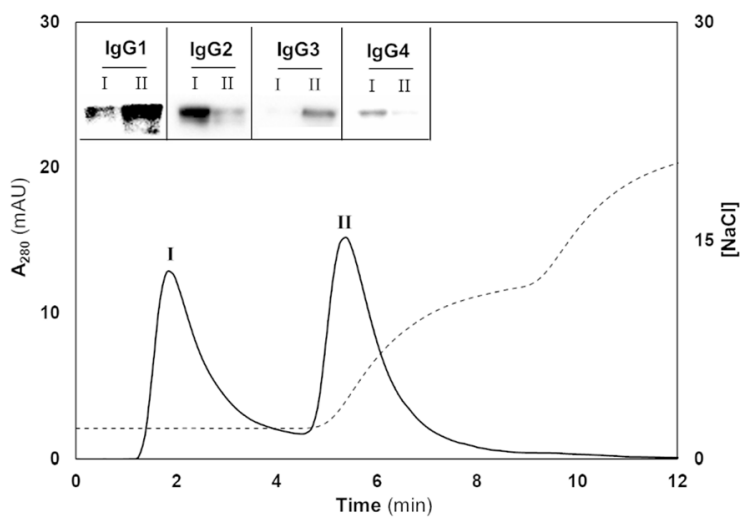

b

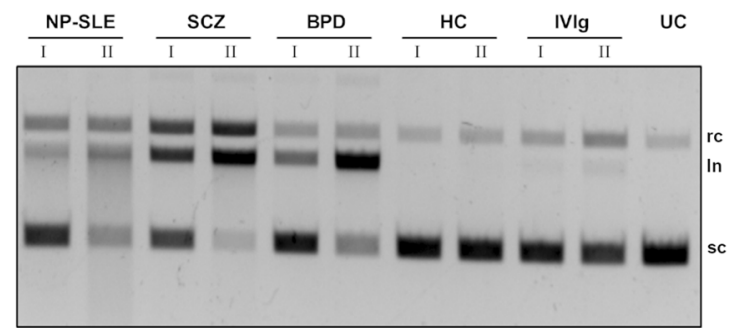

Fig. 6 IgG subclasses separation and DNA hydrolysis. a About $50 \mu \mathrm{g}$ of pre-purified total IgG Abs (twofold dilution) suspended in $25 \mathrm{mM}$ Tris- $\mathrm{HCl} \mathrm{pH} 7.4$ was fractionated and eluted using $25 \mathrm{mM}$ Tris$\mathrm{HCl} \mathrm{pH} \mathrm{7.4+0.2} \mathrm{M} \mathrm{NaCl}$. Peak I-flow-through, Peak II-elution. Inset: IgG subclasses in the peak I and II were discriminated by separate western blots. b DNA hydrolysis exhibited by peaks I (lane I) and II (lane II). UC- scDNA incubated alone; sc supercoiled DNA, rc relaxed circular DNA, In linear DNA.

an underlying inflammatory condition in our BPD participants compared to SCZ and health controls (Table 2). This data suggests presence of neuro-immuno-inflammation that is concomitant with the previously reported observations $\mathrm{s}^{5,30,31}$.

The efficiency of L-histidine ligand to discriminate the IgG subclasses as described elsewhere ${ }^{32}$ was employed, to evaluate the DNA hydrolysing activity by the IgG subclasses. Figure $6 a$ represents the chromatogram of IgG subclasses. Western blot analysis (Fig. 6a, inset) confirmed the presence of IgG2 subclass in peak I (flow-through) and IgG1 subclass in peak II (elution) fractions, respectively. Interestingly, the peak II fractions, comprising IgG1 subclass, attributed for the DNA hydrolysis in the NP-SLE, SCZ and BPD samples (Fig. 6b). On the contrary, the peak I fraction (IgG2 subclass) revealed no activity in the disease groups. However, no activity was observed in healthy controls and IVIg.

\section{DISCUSSION}

To further refine the autoimmune features in SCZ and BPD, herein, we investigated the IgG DNA abzyme activity in these patients and compared the activity profile with the IgG from NP-SLE patients. We chose to employ judiciously NP-SLE as a positive control, due to following reasons (i) evidence of association of psychiatric symptoms in a subset of SLE patients ${ }^{20}$, (ii) prevalence of antidsDNA Abs in the circulation ${ }^{33}$, and (iii) presence of DNase activity in their lgG $\mathrm{Abs}^{27}$. The bio-affinity L-histidyl chromatographic system was used due to its efficiency in recovering structurally intact and electrophoretically homogenous $\lg$ Abs and its subclasses ${ }^{32,34}$. To assess the $\operatorname{lgG}$ mediated DNase activity quantitatively, our experimental conditions were optimised to determine the antibody concentration and time course required for the scDNA hydrolysis (Fig. 4). Interestingly, the close resembles of DNase activity between SCZ and NP-SLE (Fig. 5) highlights 
Table 3. Subgroup division based on DNA hydrolysis distribution.

\begin{tabular}{|c|c|c|c|c|}
\hline \multirow[b]{2}{*}{$\begin{array}{l}\text { Scores and } \\
\text { variables }\end{array}$} & \multicolumn{2}{|c|}{ Schizophrenia } & \multicolumn{2}{|c|}{ Bipolar disorder } \\
\hline & $\begin{array}{l}\text { Above- } \\
\text { average } \\
\text { subgroup } \\
(n=12)\end{array}$ & $\begin{array}{l}\text { Below- } \\
\text { average } \\
\text { subgroup } \\
(n=19)\end{array}$ & $\begin{array}{l}\text { Above- } \\
\text { average } \\
\text { subgroup } \\
(n=11)\end{array}$ & $\begin{array}{l}\text { Below- } \\
\text { average } \\
\text { subgroup } \\
(n=20)\end{array}$ \\
\hline $\begin{array}{l}\text { PANSS } \\
\text { positive }\end{array}$ & $16.1 \pm 5.8^{\mathrm{a}}$ & $12.95 \pm 6.2$ & - & - \\
\hline $\begin{array}{l}\text { PANSS } \\
\text { negative }\end{array}$ & $17.2 \pm 8.4$ & $18.35 \pm 9$ & - & - \\
\hline $\begin{array}{l}\text { PANSS } \\
\text { general }\end{array}$ & $35.4 \pm 9$ & $30.5 \pm 10.9$ & - & - \\
\hline PANSS total & $68.7 \pm 19.3$ & $61.3 \pm 23.8$ & - & - \\
\hline $\mathrm{CDSS}^{\mathrm{b}}$ & $1 \pm 1.6$ & $1.3 \pm 2.0$ & - & - \\
\hline MADRS $^{c}$ & - & - & $6.7 \pm 10$ & $2.33 \pm 4.3$ \\
\hline YMRS $^{d}$ & - & - & $13.28 \pm 13$ & $14.87 \pm 8.8$ \\
\hline GAF & $39.4 \pm 18.4$ & $48 \pm 20.7$ & $50.85 \pm 11.1$ & $51.27 \pm 12.6$ \\
\hline IL-6 & $5.5 \pm 2.9$ & $6 \pm 5.6$ & $7.4 \pm 3.5$ & $6.6 \pm 5.8$ \\
\hline Total IgG & $11.2 \pm 4.99$ & $11.5 \pm 4.16$ & $13.25 \pm 4.5$ & $12.6 \pm 4.2$ \\
\hline $\begin{array}{l}\text { Disease } \\
\text { duration } \\
\text { (months) }\end{array}$ & $8.8 \pm 7.5$ & $8.35 \pm 7.2$ & $6.4 \pm 8.5$ & $5.07 \pm 6$ \\
\hline
\end{tabular}

partially that the IgG Abs from SCZ shares autoimmune-like features. Besides, the SCZ IgG Abs showed a twofold higher activity than the healthy controls. Our findings corroborate with a recent report by Ermakov et al. ${ }^{35}$ describing the presence of IgG DNA abzyme, studied exclusively in SCZ patients. Nevertheless, our comparative analysis of DNA hydrolysing lgG Abs (Fig. 5) from the SCZ, BPD, NP-SLE patients, and healthy controls bring robust evidence of autoimmune association not only in SCZ but also broadly in psychoses per se. Nevertheless, it was surprising to note a twofold lower DNase activity in our BPD patients compared to NP-SLE. Unexpectedly, a subset of BPD patients (41.9\%) showed DNase activity less than that of the healthy controls and IVIg. Observations of the low activity may be due to heterogeneity among the BPD patients, which hypothetically could stem from either disease severity or status of mood oscillation or effect and duration of medications that requires further insight.

Despite presence of a statistical significance among the four groups (one-way ANOVA analysis), the distribution pattern of DNase activity was surprisingly uneven in SCZ and BPD groups (Fig. 5). Based on the distribution, the above patient groups were further divided into two subgroups, namely "above-average subgroup" and "below-average subgroup" by fixing the mean as a cut-off. Subsequently, the two subgroups were analysed for a potential relationship between the psychotic disease scores and immunological parameters (Table 3). Interestingly, the SCZ aboveaverage subgroup showed a positive association with the PANSSpositive, general and total scores, while MADRS associated with the BPD above-average subgroup. Consequently, other variables between the two subgroups in the SCZ and BPD showed moderate differences without statistical significance. These data are likely to open windows for eventual patient stratification provided a much larger study is carried out with a range of psychosis spectrums, to draw appropriate conclusions.

There are some limitations to this study. First, the sample size is small and requires to be assessed with a much larger clinically well-defined cohort. Eventually, this will help in exploring a plausible spatiotemporal association between the disease characteristics and the $\lg G$ mediated activity. Second, the influence of medications on the activity along with the disease features is not explored. Third, concurrent analyses of CSF and serum samples may be warranted to examine the precise link between autoimmune process and episodes of psychosis.

Despite small sample size, our preliminary case-control results highlight the presence of DNA abzyme activity, in general, in psychoses and prominently in SCZ patients. Overall, our findings support for prospective autoimmune spectrum in SCZ and BPD patients. Altogether capability to proactively identify and stratify the psychotic patients, assisted by clinical, biological and genetic features, may contribute to improve patient care.

\section{METHODS}

\section{Study design and participants}

The objective of the present study was to evaluate the presence or absence of autoimmune comorbidity, based on catalytic antibody perspective, in SCZ and BPD patients. This was an experimental design study composed of case-control, recruited at Jawaharlal Institute of Postgraduate Medical Education \& Research (JIPMER), India. The study protocol was approved by Institutional Ethics committee of JIPMER (ECR/ 342/Inst/PY/2013) and Vellore Institute of Technology (VIT) (IECH/2014/ May23/05). Written informed consent was obtained from all the participants. The psychoses participants for the study were randomly selected from the individuals attending out-patient or in-patient services at the department of psychiatry. Patients diagnosed as SCZ and BPD, respectively and who fulfilled the study inclusion criteria i.e., Diagnostics and Statistical Manual of Mental disorder, IV edition (DSM IV) ${ }^{36}$, absence of any autoimmune disorder, inflammatory, and other neurological disorders were only recruited. A subset of systemic lupus patients with diffused psychiatric/neuropsychological syndromes ${ }^{37}$ (anxiety disorder, acute confusion status, cognitive disorder, mood disorder, and psychosis) were enrolled as disease comparator group at the department of clinical immunology. The clinical, demographic, biochemical, and medication profiles were collected at the time of enrolment from all the participants (Table 1), and were blinded to the investigators performing DNA abzyme studies until the analyses were completed. About $0.5 \mathrm{~mL}$ of serum was prepared from a non-fasting blood collected from the SCZ $(n=31)$, BPD $(n=31)$, and NP-SLE $(n=20)$ patients, respectively. Healthy controls $(n=$ 25) without a personal or family history of psychotic disorders and autoimmune disorders were also recruited at JIPMER. All the samples were of south Indian ethnicity.

\section{IgG antibody purification}

The bio-affinity ligand L-histidine was covalently coupled to $\mathrm{CIM}^{\oplus}$ monolithic disk (BIA Separations d.o.o, Slovenia) bearing CDI chemistry ${ }^{34}$ to obtain a CIM-histidyl column. This chromatographic column was used for the purification of IgG Abs directly from serum. The purification experiment was carried out with an automated AKTA FPLC system (GE Healthcare, USA), integrated with a binary pump, UV detector, conductivity and fraction collector. The operation and acquisition of data were controlled by inbuilt UNICORN 5.0 software.

Briefly, about $150 \mu \mathrm{L}$ of serum diluted tenfold in $25 \mathrm{mM}$ MOPS buffer $\mathrm{pH}$ 6.5 was injected into CIM-histidyl column that was pre-equilibrated with the same buffer at a flow rate of $4 \mathrm{~mL} / \mathrm{min}$. The unbound proteins were washed away with the above buffer until the UV absorbance $(280 \mathrm{~nm})$ reached the baseline. The adsorbed proteins were eluted in a step gradient manner using $\mathrm{NaCl}(0.2$ and $0.4 \mathrm{M})$ added in $25 \mathrm{mM}$ MOPS buffer pH 6.5. Successively, the column was regenerated using $0.5 \mathrm{M} \mathrm{NaOH}$. The eluted fractions were desalted and concentrated using Amicon Ultra-4 $10 \mathrm{~K}$ centrifugal filter unit (Merck Millipore Bioscience, India). Protein concentration was determined by Bradford assay. The purity of IgG was analysed on SDS-PAGE (10\%) under both non-reducing and reducing (DTT treatment) conditions. The gels were derived from the same experiments and they were processed in parallel. Under similar conditions IVIg (GAMUNEX-C, Girfols Inc., USA) was also subjected to purification and analysis.

\section{IgG subclass purification}

Novarose (Inovata, Sweden) matrix immobilised with bio-affinity ligand L-histidine was used for the separation of IgG subclasses, as demonstrated 
earlier $^{32}$. The pre-purified total IgG Abs (above section) was buffer exchanged with $25 \mathrm{mM}$ Tris- $\mathrm{HCl}$ buffer $\mathrm{pH} 7.4$, using Amicon Ultra-4 $10 \mathrm{~K}$ device. The Novarose histidyl gel was packed into a glass column $(1 \times$ $1 \mathrm{~cm}$ ) and was equilibrated with $25 \mathrm{mM}$ Tris- $\mathrm{HCl}$ buffer $\mathrm{pH}$ 7.4. The enriched total IgG Abs $(50 \mu \mathrm{g} / 50 \mu \mathrm{l})$ was diluted twofold in the equilibration buffer and re-chromatographed on Novarose histidyl column. The bound proteins were eluted using 0.1 and $0.2 \mathrm{M} \mathrm{NaCl}$ dissolved in the equilibration buffer in a step gradient manner. A flow rate of $1 \mathrm{~mL} / \mathrm{min}$ was used and fractions of $0.25 \mathrm{~mL}$ were collected. Both, the flow-through and the eluted fractions were concentrated using Amicon Ultra-4 $10 \mathrm{~K}$ device and subjected to SDS-PAGE analysis (10\%) under non-reducing conditions. Individual, IgG subclasses were identified by western blot using human IgG subclass specific HRP conjugated Abs (Janssen Biochemica, Belgium) at a dilution of 1:10,000, which were processed with the study controls. Chemiluminescent substrate (BioRad, USA) was used for detection.

\section{IL-6 and anti-dsDNA measurement}

The IL- 6 was measured using Human IL- 6 ELISA Kit (Diaclone, France) as per manufacturer instructions. IMTEC-dsDNA-Antibodies ELISA kit (Germany) was used for measuring anti-dsDNA titre, according to the manufacturer instructions.

\section{Serum total IgG measurement}

Maxisorp 96-well plate (Nunc, Denmark) was coated with goat anti-human $\gamma$-chain specific Abs (P.A.R.I.S, France) diluted at 1:30,000 with phosphatebuffered saline, pH7.4 (PBS). Following overnight incubation at $4{ }^{\circ} \mathrm{C}$, the plate was washed with PBS/0.05\% V/V Tween20 (PBS-T) and blocked with $5 \%(\mathrm{w} / \mathrm{v})$ skimmed milk for $2 \mathrm{~h}$ at $37^{\circ} \mathrm{C}$. About $100 \mu \mathrm{L}$ of diluted $(1: 40,000$ in PBS) patient and healthy serum were added to individual wells and the plate was incubated at $37^{\circ} \mathrm{C}$ for $1 \mathrm{~h}$. Next, the plate was washed and probed for $1 \mathrm{~h}$ with rabbit antihuman IgG HRP conjugate Abs (Sigma, USA) at $37^{\circ} \mathrm{C}$. The chromogenic substrate, tetramethylbenzidine (TMB) (Merck, India) was used for detection. The microplate was read at $450 \mathrm{~nm}$ using Enspire microplate reader (PerkinElmer, USA). Experiments were performed in duplicates and the absorbance was noted. Total human IgG Abs (Cohn fraction II, III) (Sigma, USA) was used to plot a standard curve. The concentration of total $\lg G$ in the patient groups, as well as healthy control serum was determined from the standard curve.

\section{DNA hydrolysis assay}

The assay was performed in a $20 \mu \mathrm{L}$ reaction mixture consisting of $50 \mathrm{ng}$ of plasmid DNA pUC18 (>80\% supercoil form) (Merck, India) and $2 \mu \mathrm{g}$ of affinity purified total $\mathrm{lgG}$ Abs from the patient and control samples, respectivel $\mathrm{y}^{27}$. The reaction buffer comprised $20 \mathrm{mM}$ Tris- $\mathrm{HCl} \mathrm{pH} \mathrm{7.5,1} \mathrm{mM}$ ethylenediaminetetraacetic acid (EDTA) and $5 \mathrm{mM} \mathrm{MgCl}$. As controls, IVlg with DNA and DNA alone in the reaction buffer were incubated along with other samples. The assay was performed at $37^{\circ} \mathrm{C}$ for $2 \mathrm{~h}$. The IgG subclass fractions obtained from re-chromatographed experiments were subjected to DNA hydrolysis assay under similar conditions except for the incubation time that was $1 \mathrm{~h}$.

The digested DNA products were resolved on a $0.8 \%$ agarose gel electrophoresis (AGE) and were visualised by ethidium bromide stain. The gel image was captured using Chemidoc ${ }^{\mathrm{TM}}$ MP imaging system.

\section{Concentration and time-dependent assays}

For the concentration assay, about $50 \mathrm{ng}$ of plasmid DNA pUC18 (substrate) was added to the increasing concentration of total IgG Abs $(1-6 \mu \mathrm{g})$ in a $20 \mu \mathrm{L}$ reaction buffer $(20 \mathrm{mM}$ Tris- $\mathrm{HCl} \mathrm{pH} \mathrm{7.5,1} \mathrm{mM} \mathrm{EDTA} \mathrm{and}$ $5 \mathrm{mM} \mathrm{MgCl}{ }_{2}$ ). The reaction mixture was incubated for $2 \mathrm{~h}$ at $37^{\circ} \mathrm{C}$.

For the time-dependent assay, total lgG Abs $(5 \mu \mathrm{g} / 100 \mu \mathrm{L})$ and plasmid DNA, pUC18 $(250 \mathrm{ng} / 100 \mu \mathrm{L})$ were constituted in $100 \mu \mathrm{L}$ reaction buffer and was incubated at $37^{\circ} \mathrm{C}$ for $1 \mathrm{~h}$. Aliquots of $20 \mu \mathrm{L}$ were drawn at the time intervals of $0,15,30,45$, and $60 \mathrm{~min}$ and the reaction was stopped by deep freezing. These assays were performed with IgG Abs from the disease groups and healthy control.

Finally, the digested DNA products were resolved on $0.8 \%$ AGE, visualised by ethidium bromide stain and image was captured using geldoc. The density of the intact scDNA was fixed as a standard (100\%) to calculate the percentage hydrolysis of scDNA mediated by IgG Abs in a relative quantity mode using Image lab $^{\mathrm{TM}}$ software.

\section{Statistical analysis}

Shapiro-Wilk's test was used to check the Gaussian distribution of the analysed data. Samples that met the criteria of Gaussian distribution were analysed by Student's $t$-test and those that did not meet the criteria were analysed by Mann-Whitney $U$-test. IgG mediated DNA hydrolysis of the four groups were analysed by one-way ANOVA test. GraphPad Prism 6 was used for statistically analysis and $p<0.05$ was considered significant.

\section{Reporting summary}

Further information on research design is available in the Nature Research Reporting Summary linked to this article.

\section{DATA AVAILABILITY}

The data that supports the findings of this study are available from the corresponding author upon reasonable request and will be made available with prior permission from the JIPMER, India.

Received: 22 September 2020; Accepted: 15 January 2021; Published online: 26 February 2021

\section{REFERENCES}

1. Müller, N., Weidinger, E., Leitner, B. \& Schwarz, M. J. The role of inflammation in schizophrenia. Front. Neurosci. 9, 372 (2015).

2. Muneer, A. Bipolar disorder: role of inflammation and the development of disease biomarkers. Psychiatry Investig. 13, 18-33 (2016).

3. Strous, R. D. \& Shoenfeld, Y. Schizophrenia, autoimmunity and immune system dysregulation: a comprehensive model updated and revisited. J. Autoimmun. 27, 71-80 (2006).

4. Cullen, A. E. et al. Associations between non-neurological autoimmune disorders and psychosis: a meta-analysis. Biol. Psychiatry 85, 35-48 (2019).

5. Goldsmith, D. R., Rapaport, M. H. \& Miller, B. J. A meta-analysis of blood cytokine network alterations in psychiatric patients: comparisons between schizophrenia, bipolar disorder and depression. Mol. Psychiatry 21, 1696-1709 (2016).

6. Jeppesen, R. \& Benros, M. E. Autoimmune diseases and psychotic disorders. Front. Psychiatry 10, 131 (2019).

7. Müller, N. \& Schwarz, M. J. Immune system and schizophrenia. Curr. Immunol. Rev. 6, 213-220 (2010).

8. Oliveira, J., Oliveira-Maia, A. J., Tamouza, R., Brown, A. S. \& Leboyer, M. Infectious and immunogenetic factors in bipolar disorder. Acta Psychiatr. Scand. 136, 409-423 (2017).

9. Pape, K., Tamouza, R., Leboyer, M. \& Zipp, F. Immunoneuropsychiatry-novel perspectives on brain disorders. Nat. Rev. Neurol. 15, 317-328 (2019).

10. Zandi, M. S. et al. Immunotherapy for patients with acute psychosis and serum NMethyl D-Aspartate receptor (NMDAR) antibodies: a description of a treated case series. Schizophr. Res. 160, 193-195 (2014).

11. Pollak, T. A. et al. Antibodies in the diagnosis, prognosis, and prediction of psychotic disorders. Schizophr. Bull. 45, 233-246 (2019).

12. Wagnon, I. et al. Autoimmune encephalitis mediated by B-cell response against N-methyl-d-aspartate receptor. Brain 143, 2957-2972 (2020).

13. Al-Diwani, A. A. J., Pollak, T. A., Irani, S. R. \& Lennox, B. R. Psychosis: an autoimmune disease? Immunology 152, 388-401 (2017).

14. Jones, A. L., Mowry, B. J., Pender, M. P. \& Greer, J. M. Immune dysregulation and self-reactivity in schizophrenia: do some cases of schizophrenia have an autoimmune basis? Immunol. Cell Biol. 83, 9-17 (2005).

15. Jézéquel, J., Johansson, E. M., Leboyer, M. \& Groc, L. Pathogenicity of antibodies against NMDA receptor: molecular insights into autoimmune psychosis. Trends Neurosci. 41, 502-511 (2018).

16. Zong, S. et al. Neuronal surface autoantibodies in neuropsychiatric disorders: are there implications for depression? Front. Immunol. 8, 752 (2017).

17. Pearlman, D. M. \& Najjar, S. Meta-analysis of the association between N-methyl-daspartate receptor antibodies and schizophrenia, schizoaffective disorder, bipolar disorder, and major depressive disorder. Schizophr. Res. 157, 249-258 (2014).

18. Pollak, T. A. et al. Autoimmune psychosis: an international consensus on an approach to the diagnosis and management of psychosis of suspected autoimmune origin. Lancet Psychiatry 7, 93-108 (2020).

19. Murphy, R. et al. Neuropsychiatric syndromes of multiple sclerosis. J. Neurol. Neurosurg. Psychiatry 88, 697-708 (2017).

20. Pego-Reigosa, J. M. \& Isenberg, D. A. Psychosis due to systemic lupus erythematosus: characteristics and long-term outcome of this rare manifestation of the disease. Rheumatology 47, 1498-1502 (2008). 
21. Beasley, S. J. \& Greer, J. M. Autoantibodies and their potential roles in diseases of the nervous system. Clin. Exp. Neuroimmunol. 6, 370-386 (2015).

22. Nestor, J. et al. Lupus antibodies induce behavioral changes mediated by microglia and blocked by ACE inhibitors. J. Exp. Med. 215, 2554-2566 (2018).

23. DeGiorgio, L. A. et al. A subset of lupus anti-DNA antibodies cross-reacts with the NR2 glutamate receptor in systemic lupus erythematosus. Nat. Med. 7, 1189-1193 (2001).

24. Mader, S., Brimberg, L. \& Diamond, B. The role of brain-reactive autoantibodies in brain pathology and cognitive impairment. Front. Immunol. 8, 1101 (2017).

25. Paul, S., Planque, S. A., Nishiyama, Y., Hanson, C. V. \& Massey, R. J. Nature and nurture of catalytic antibodies. Adv. Exp. Med. Biol. 750, 56-75 (2012).

26. Hanson, C. V., Nishiyama, Y. \& Paul, S. Catalytic antibodies and their applications. Curr. Opin. Biotechnol. 16, 631-636 (2005).

27. Ponomarenko, N. A. et al. Catalytic antibodies in clinical and experimenta pathology: human and mouse models. J. Immunol. Methods 269, 197-211 (2002).

28. Pradhan, V. et al. Catalytic antibodies in patients with systemic lupus erythematosus. Eur. J. Rheumatol. 5, 173-178 (2018).

29. Wootla, B. et al. Autoantibodies with enzymatic properties in human autoimmune diseases. J. Autoimmun. 37, 144-150 (2011).

30. Hamdani, N. et al. Immunoglobulin sub-class distribution in bipolar disorder and schizophrenia: potential relationship with latent Toxoplasma Gondii infection. BMC Psychiatry 18, 239 (2018).

31. Wadee, A. A. et al. Serological observations in patients suffering from acute manic episodes. Hum. Psychopharmacol. 17, 175-179 (2002).

32. Kamalanathan, A. S. \& Vijayalakshmi, M. A. Molecular studies of rheumatoid factor using pseudobioaffinity membrane chromatography. J. Mol. Recognit. 22, 146-153 (2009).

33. Rekvig, O. P. Anti-dsDNA antibodies as a classification criterion and a diagnostic marker for systemic lupus erythematosus: critical remarks. Clin. Exp. Immunol. 179, 5-10 (2015)

34. Prasanna, R. R., Kamalanathan, A. S. \& Vijayalakshmi, M. A. Development of L-histidine immobilized $\mathrm{CIM}^{(\oplus)}$ monolithic disks for purification of immunoglobulin G. J. Mol. Recognit. 28, 129-141 (2015).

35. Ermakov, E. A. et al. DNA-hydrolysing activity of lgG antibodies from the sera of patients with schizophrenia. Open Biol. 5, 150064 (2015).

36. American Psychiatric Association. Diagnostic and Statistical Manual of Mental Disorders, Fourth Edition (DSM-IV) (American Psychiatric Publishing, Inc., 1994).

37. West, S. G., Emlen, W., Wener, M. H. \& Kotzin, B. L. Neuropsychiatric lupus erythematosus: a 10-year prospective study on the value of diagnostic tests. Am. J. Med. 99, 153-163 (1995).

\section{ACKNOWLEDGEMENTS}

One of the authors, Ramesh R, wishes to thank the Council of Scientific and Industrial Research (CSIR), Govt. of India for senior research fellowship. Intravenous Immunoglobulin (IVIg) (GAMUNEX-C, Girfols Inc., CA, USA) was a kind gift by
Dr. Jagadeesh Bayry, INSERM, Paris, France. This work was supported by Indo-French Centre for the Promotion of Advanced Research (IFCPAR)/Centre Franco-Indien pour la Promotion de la Recherche Avancée (CEFIPRA) with project No. 5103-I.

\section{AUTHOR CONTRIBUTIONS}

R.R. executed the experimental works. A.S., R.P.R., and V.S.N. were responsible for clinical data collection and serum sample collection. R.P.R., V.S.N., V.M.A., R.K., R.T., M.L., and K.A.S. contributed for the conception and the study design. R.R., K.A.S., R.P.R., V.S.N., and R.K. interpreted and analysed the data and drafted the manuscript, while other authors provided critical inputs. All the authors provided significant intellectual inputs and approved the final manuscript.

\section{COMPETING INTERESTS}

The authors declare no competing interests.

\section{ADDITIONAL INFORMATION}

Supplementary information The online version contains supplementary materia available at https://doi.org/10.1038/s41537-021-00143-6.

Correspondence and requests for materials should be addressed to A.S.K.

Reprints and permission information is available at http://www.nature.com/reprints

Publisher's note Springer Nature remains neutral with regard to jurisdictional claims in published maps and institutional affiliations.

Open Access This article is licensed under a Creative Common Attribution 4.0 International License, which permits use, sharing, adaptation, distribution and reproduction in any medium or format, as long as you give appropriate credit to the original author(s) and the source, provide a link to the Creative Commons license, and indicate if changes were made. The images or other third party material in this article are included in the article's Creative Commons license, unless indicated otherwise in a credit line to the material. If material is not included in the article's Creative Commons license and your intended use is not permitted by statutory regulation or exceeds the permitted use, you will need to obtain permission directly from the copyright holder. To view a copy of this license, visit http://creativecommons. org/licenses/by/4.0/.

(c) The Author(s) 2021 